\title{
XYLAN RECOVERY FROM DILUTE NITRIC ACID PRETREATED OIL PALM FROND BAGASSE USING FRACTIONAL FACTORIAL DESIGN
}

\author{
NURUL AISHAH MAZLAN*; KAMALIAH ABDUL SAMAD*; HAFIZUDDIN WAN YUSSOF*; \\ ROZAIMI ABU SAMAH ${ }^{\star *}$ and JAMALIAH MD JAHIM ${ }^{\ddagger}$
}

\begin{abstract}
Pretreatment enhances bioconversion of lignocellulosic biomass by disrupting and changing the properties of its material. This work is intended to examine the influence of several variables involved in the recovery of xylan from oil palm frond bagasse (OPFB) in the pretreatment of diluted nitric acid. Through a fractional factorial design of $2^{5-1}$ the temperature variables ranged from $37^{\circ} \mathrm{C}-90^{\circ} \mathrm{C}$, time of reaction varied from $6-24$ $\mathrm{hr}$, solid loading ranged from $5 \%-20 \%$, concentration of acid changed from $0.01 \%-1.0 \%$, and agitation between yes or no were evaluated. As much as $27.63 \%$ of xylan successfully recovered at mild condition and it was completely hydrolysed as the pretreatment condition increased. This study found solid loading of 5\% and acid concentration of $0.01 \%$ at $37^{\circ} \mathrm{C}$ for $24 \mathrm{hr}$ pretreatment without agitation were best to maximise xylan recovery and minimise lignin content simultaneously. Temperature was the most important factor studied for the recovery of xylan with a contribution of $29.34 \%$. The findings suggest that studying the condition influencing acid pretreatment is crucial towards improving pretreatment process.
\end{abstract}

Keywords: acid pretreatment, fractional factorial design, lignin removal, oil palm frond bagasse, xylan recovery.

Received: 3 March 2020; Accepted: 28 August 2020; Published online: 27 October 2020.

\section{INTRODUCTION}

Studies on alternative biochemical approaches have been given much attention recently due to the increasing awareness on the environmental degradation created by the use of traditional petrochemical processes in chemical production. Biorefinery is considered as one of the promising

* Faculty of Chemical and Process Engineering Technology, Universiti Malaysia Pahang, Lebuhraya Tun Razak, 26300 Gambang, Kuantan, Pahang, Malaysia.

E-mail: hafizuddin@ump.edu.my

** Department of Chemical Engineering, College of Engineering, Universiti Malaysia Pahang, Lebuhraya Tun Razak, 26300 Gambang, Kuantan, Pahang, Malaysia.

‡ Department of Chemical and Process Engineering, Faculty of Engineering and Built Environment, Universiti Kebangsaan Malaysia, 43600 UKM Bangi, Selangor, Malaysia. processes in converting biomass or other renewable resources into fuel and chemicals which simultaneously can reduce carbon footprint. In several tropical countries especially in the Asian region, the oil palm industry produces a substantial amount of biomass that can be used for bio conversion. The industry generates several types of biomass and one of the most recently studied is the oil palm frond (OPF), due to its availability and valuable content. During the pruning operation, OPF can be obtained yearly up to about 44 million tonnes and $15 \mathrm{t} \mathrm{ha}^{-1}$ during replanting (Awalludin et al., 2015). These biomass if not utilised will contribute to the environmental degradation because it will only be left rotten or burned in landfills (Faizi et al., 2017). Since 1991, OPF has been a subject of research as feed for farm animals and sorption agent. However, in 2010, OPF was identified as a potential source for fermentable sugar production (Goh et al., 2010). Lignocellulosic biomass has recently received significant attention as a source for the processing 
of various chemicals in biorefineries (Asim et al., 2019; Dai et al., 2019; Noorshamsiana et al., 2017; Solarte-Toro et al., 2018). Lignocellulosic biomass is a plant dry matter of which cellulose, hemicellulose and lignin are the primary polymers that make up its complex biomatrix structure (Agbor et al., 2011). Since OPF contains $44.8 \%$ glucan, $19.45 \%$ xylan and $19.53 \%$ lignin, it has become a source in many other products such as bioethanol (Soplah et al., 2015), succinic acid (Tan et al., 2016), glucose (Wan Omar and Amin, 2016), xylitol and furfural (Swain and Krishnan, 2015; Zhang et al., 2017). However, the conversion may be restricted due to the resistance of the complex molecule structure of lignin to chemical and enzyme attacks. Hence, most of the chemical processes that use lignocellulosic biomass as a source should consider to remove lignin as much as possible for the process to be successful (Wan Omar and Amin, 2016).

Many processes have been implemented to convert lignocellulosic materials into valuable products. Usually, the process starts with pretreatment of the biomass aiming at the deconstruction of its plant cell wall. Two categories of pretreatment are identified, namely chemical and mechanical pretreatment. The initial step in pretreatment typically involves mechanical process where the biomass will be chipped, ground or milled to reduce its size (Kumari and Singh, 2018). Chemical treatment through acid, alkali and ionic liquid treatment is then used to break down the biomass chemical structure (Kumari and Singh, 2018). Alkaline pretreatment is the viable technique to break the components in biomass, especially if the process requires to isolate xylan (Carvalho et al., 2013). Using the alkaline treatment, xylan was successfully extracted from corn stover (Lee et al., 2015), oat straw (Romaní et al., 2016), arecanut husk (Singh et al., 2018) and hardwood (Rajagopalan et al., 2017). Nevertheless, Kumar et al. (2009) mentioned that dilute acid pretreatment was also practical and this process is proven to be successful in altering and exposing the structure in biomass. Furthermore, dilute acid pretreatment is more economical. To date, the application of nitric acid in pretreatment processes has been far too little considered. Nitric acid pretreatment has been proven to shorten the overall treatment process and inhibit the formation of inhibitors thus, improving production yield (Zhang et al., 2011). On top of that, Xiao and Clarkson (1997) reported that nitric acid pretreatment may contribute to solubilisation of huge amount of lignin from the substrate. The findings show that the method has potential in lignin removal which indirectly exposes hemicellulose surface to the enzyme attack in the enzymatic hydrolysis for xylan based products such as xylooligosaccharides. However, since several factors may influence the pretreatment process, screening the most influential factor is a critical step that must be considered to improve the pretreatment process.

One of the best experimental design to quickly study the effects of different factors simultaneously is the use of response surface methodology (RSM) through factorial design (Abu Sepian et al., 2019). In fact, factorial design, a tool provided by Design Expert software is also useable to evaluate the interaction between the factors involve in a process efficiently (Box and Wilson, 1951). Design Expert has been widely adopted to improve various pretreatment methods (Lyu et al., 2018; Mesa et al., 2017; Soares et al., 2017) of numerous types of raw material by evaluating and selecting its best operational condition. However, limited studies on the use of factorial has been performed using acid pretreatment to retain xylan in solid waste for further enzymatic hydrolysis. Martín et al. (2019) demonstrated that acid concentration of $1 \%$ could lead to complete hydrolysation of xylan compared to a lower acid concentration. Hernández et al. (2013) claimed that xylan can be retained in solids only by implementing mild conditions pretreatment, since the product can be easily hydrolysed during pretreatment. However, it is still not clear whether the use of mild operational conditions may retain higher xylan since there are very few studies focussing on xylan recovery in solids. Therefore, this study was performed to address the research gaps by investigating the significance of several factors including temperature, reaction time, solid loading, acid concentration, and agitation on the pretreatment of dilute nitric acid using two-level factorial design in oil palm frond bagasse (OPFB). A $2^{5-1}$ fractional factorial design (FFD) was applied with 16 runs of experiment.

\section{MATERIALS AND METHODS}

\section{Materials}

This study used OPF from a nearby plantation in Kuantan, Pahang, Malaysia. To get the OPFB, the OPFB was squeesed to remove the OPF juice with a sugar cane pressing unit. The obtained bagasse was then sun-dried for three days until the moisture content of OPFB was less than 10\%. After the drying process, the OPFB was ground to get OPFB fibre and then sieved to ensure that the thickness of the OPFB was less than $2 \mathrm{~mm}$. The sieved OPFB was then stored in $-20^{\circ} \mathrm{C}$ until further use.

\section{Factorial Analysis for Acid Pretreatment}

A factorial study was conducted with a Design Expert software, version 7.0 (Stat-Ease Inc., USA) to study the acid pretreatment process for the recovery of xylan. A $2^{5-1}$ fractional factorial design 
was used to assess the statistical significance of five parameters including temperature, reaction time, solid loading, acid concentration and agitation. The raw OPFB fibre was soaked in diluted nitric acid at concentrations between $0.01 \%$ and $1.0 \%$, while the solid loading ranged between $5 \%$ and $20 \%$. The acid pretreatment of OPFB was conducted for 6-24 hr at $37^{\circ} \mathrm{C}-90^{\circ} \mathrm{C}$ in a water bath with $(200 \mathrm{rpm})$ and without agitation. Once the pretreatment process was completed, the substrate was then washed thoroughly with tap water for neutralisation. The sample was then placed in a $60^{\circ} \mathrm{C}$ drying oven for one day before further analysis. Three components, which include glucan $\left(\%, \mathrm{~g} \mathrm{~g}^{-1}\right)$, xylan $\left(\%, \mathrm{~g} \mathrm{~g}^{-1}\right)$ and lignin $\left(\%, \mathrm{~g} \mathrm{~g}^{-1}\right)$ were assessed to improve xylan recovery. Sixteen assessments were undertaken in this work. Table 1 lists the coded values of various experimental variables.

TABLE 1. CODED VALUES AND ACTUAL VALUES OF VARIOUS PRETREATMENT FACTORS

\begin{tabular}{lcccc}
\hline \multicolumn{1}{c}{ Factors } & $\begin{array}{c}\text { Type of } \\
\text { factor }\end{array}$ & \multicolumn{2}{c}{ Actual values } & \multirow{2}{*}{ Units } \\
\cline { 3 - 4 } & $\mathbf{( - 1 )}$ & $\mathbf{( + 1 )}$ & \\
\hline A: Temperature & Numerical & 37 & 90 & ${ }^{\circ} \mathrm{C}$ \\
B: Reaction time & Numerical & 6 & 24 & $\mathrm{hr}$ \\
C: Solid loading & Numerical & 5 & 20 & $\%(\mathrm{w} / \mathrm{v})$ \\
$\begin{array}{l}\text { D: Acid } \\
\text { concentration }\end{array}$ & Numerical & 0.01 & 1.00 & $\%(\mathrm{v} / \mathrm{v})$ \\
E: Agitation & Categorical & No & Yes & $\mathrm{rpm}$ \\
& & & $(200)$ & \\
\hline
\end{tabular}

\section{Determination of Lignocellulosic Biomass Composition}

The analysis of glucan, xylan and lignin composition was performed following the National Renewable Energy Laboratory (NREL) procedure. The sample was first subjected to two-step extraction process with $8 \mathrm{hr}$ water extraction in the first step, followed by $24 \mathrm{hr}$ extraction using ethanol in the second step. The biomass was dried overnight in an oven at $60^{\circ} \mathrm{C}$ between the two extractions. The extraction process was done to remove extractives in the sample to prevent interference during analysis (Sluiter et al., 2008).

The extracted sample was put through acid hydrolysis to extract structural carbohydrates and determine the amount of lignin in biomass using $72 \%$ sulphuric acid $\left(\mathrm{H}_{2} \mathrm{SO}_{4}\right)$ (Sluiter et al., 2012). In this process, $3 \mathrm{ml}$ of the acid was first added into $0.3 \mathrm{~g}$ of the free extractive sample for incubation process with a temperature of $30^{\circ} \mathrm{C}$. After $1 \mathrm{hr}$ of incubation, the incubated mixture subsequently was mixed with distilled water up to $84 \mathrm{ml}$ before being autoclaved at $121^{\circ} \mathrm{C}$ for $1 \mathrm{hr}$. The hydrolysate containing carbohydrates (glucose as an acid hydrolysis product of glucan and xylose as an acid hydrolysis product of xylan) was analysed using Agilent 1200 high-performance liquid chromatography (HPLC). Glucan and xylan content in biomass were determined using Equation (1) and (2).

$$
\begin{aligned}
& \text { Glucan }(\%)=\frac{0.9 \times V \times H_{\text {Glucan }}}{S R S_{\text {Glucan }} \times H M} \times 100 \% \quad \text { Equation (1) } \\
& \text { Xylan }(\%)=\frac{0.88 \times V \times H_{X y l a n}}{S R S_{\text {Xylan }} \times H M} \times 100 \% \quad \text { Equation (2) }
\end{aligned}
$$

where $V$ is defined as total volume of acid and ultrapure water in the vial (L), $H$ is concentration of structural carbohydrate after acid hydrolysis ( $\mathrm{g}$ litre $\left.^{-1}\right), S R S$ is sugar recovery standard and $H M$ is the mass of biomass added to the hydrolysis vial on unextracted basis.

The autoclaved acid hydrolysis solution was vacuum filtered to obtain the remaining solid. Filter paper $0.22 \mu \mathrm{m}$, cellulose ester was used for the filtration and the weight of filter paper was recorded. Deionised water was used to quantitatively rinse solid particles from vial and inside filtration cup. Solid residue is considered as a remaining lignin in the biomass. Solid sample obtained was dried in an oven at $105^{\circ} \mathrm{C}$ until a constant weight is achieved, usually a minimum of $4 \mathrm{hr}$. The weight of solid residue with filter paper was recorded. The acid insoluble lignin content was calculated according to Equation (3).

$$
\operatorname{Lignin}(\%)=\frac{L_{2}-L_{1}}{H M} \times 100 \%
$$

Equation (3)

where $L_{1}$ is filter paper $(\mathrm{g})$ and $L_{2}$ is dried solid residue with filter paper $(\mathrm{g})$.

\section{Quantification of Structural Carbohydrates}

Rezex RHM-Monosaccharide $\mathrm{H}+, 300 \times 7.8 \mathrm{~mm}$ HPLC column (Phenomenex) was used together with a refractive index (RI) detector. Deionised water with $5 \mu \mathrm{l}$ injection volume was used as the mobile phase at $0.4 \mathrm{ml} \mathrm{min}{ }^{-1}$ flow rate with the column temperature was maintained at $60^{\circ} \mathrm{C}$ and $30^{\circ} \mathrm{C}$ for RI detector. Standard solutions were prepared with concentrations in the range of 0.5-10 g litre ${ }^{-1}$ to develop calibration curves. The standard curves obtained were used to measure concentrations of glucan $\left(\mathrm{g}\right.$ litre $\left.^{-1}\right)$ and xylan $\left(\mathrm{g} \mathrm{litre}^{-1}\right)$ in the samples. 


\section{RESULTS AND DISCUSSION}

\section{Characterisation of OPFB}

It is necessary to carry out a characterisation analysis in this study in order to ensure that the significance of xylan could be retrieved later. Table 2 presents the chemical compositions of OPFB including several other raw lignocellulosic biomasses. OPFB consisted of $42.8 \%$ glucan, $20.9 \%$ xylan, $31.9 \%$ lignin, $0.8 \%$ ash and $3.6 \%$ extractives. Glucan content in OPFB was comparable with that in sugarcane bagasse $(41.95 \%)$ but higher than those in rice straw, corn stover, and wheat straw. However, xylan composition in OPFB was higher than those in rice straw and corn stover. It is important to predetermine the composition of xylan from raw OPFB by comparing it with other raw lignocellulosic biomass to ensure that high xylan is retrieved through this pretreatment study. The selection of the OPFB as raw material is beneficial since the xylan observed in this study is worth and reasonable to be recovered. However, the lignin content was high in OPFB. High lignin content may hinder the extraction of xylan due to the formation of lignin-carbohydrate complex between lignin and hemicellulose (Syazana Mohtar et al., 2017). Although OPFB contains a higher amount of lignin, ash was the lowest in the biomass. Low ash content could positively affect the pretreatment process. This is because the presence of high ash during pretreatment can cause nitric acid to neutralise alkaline ash during pretreatment rather than acid hydrolysis which may reduce the efficacy of pretreatment (He et al., 2014). A low amount of extractives in OPFB is also preferable since a high content of extractives may result in the hydrolysation of extractives instead of lignin removal (MartínezPatiño et al., 2018). Therefore, low content of ash and extractives in OPFB are important to improve the recovery of xylan through acid pretreatment by an increase in the acid hydrolysis process.

\section{Xylan Recovery from Pretreated OPFB}

Diluted nitric acid pretreatment with milder conditions was performed with the intention to achieve higher xylan recovery through higher lignin removal which occurred by disrupting the structure of OPFB. Delignification is expected to occur during pretreatment as the lignin component could become an enzyme inhibitor that prevents enzymatic hydrolysis in a further step towards the production of valuable products such as xylooligosaccharides (Wojtusik et al., 2017). The primary goal of this research was to improve xylan recovery by controlling the pretreatment process condition with the assistance of Design Expert software. Maximising the xylan recovery by diluted nitric acid pretreatment was therefore assessed by simultaneously minimising lignin to ensure pretreatment effectiveness without considering the content of glucan. Glucan is supposed to be retained in this study as the mild condition used may protect the cellulose structure and thus, prevent its hydrolysis (Xu et al., 2013).

Table 3 shows the components (glucan, xylan and lignin contents) obtained via $2^{5-1}$ fractional factorial design. The chemical compositions observed varied significantly between the experimental set of different processes with glucan, xylan and lignin values ranging from $47.06 \%-73.33 \%, 0.00 \%-27.63 \%$ and $15.03 \%-31.33 \%$, respectively. The highest recovery of xylan $(27.63 \%)$ was found at pretreatment condition of $37^{\circ} \mathrm{C}$ with solid loading and acid concentration of $5 \%$ and $0.01 \%$ for $24 \mathrm{hr}$ without agitation (Standard Order 3). At the same condition, the lignin content of OPFB was hydrolysed to minimum $(15.03 \%)$ which caused the increase of glucan content to $57.02 \%$. The results show that the mild acid pretreatment condition was appropriate to remove lignin by producing phenolic compounds such as $p$-coumaric, ferulic and diferulic acids that contributed to crosslinking between lignin-hemicellulose binding. The cleavage of lignin from hemicellulose and cellulose by releasing the phenolic compounds indicated an increase in the efficiency of acid pretreatment which results in the exposure of the hemicellulose surface (Jönsson and Martín, 2016).

Results also showed that complete xylan removal occurred at standard order run 8 and 16 when zero percent of xylan was achieved at these two experimental runs. At Standard Order 8, the experiment was conducted using $20 \%$ solid loading

TABLE 2. CHEMICAL COMPOSITION OF VARIOUS RAW LIGNOCELLULOSIC BIOMASS

\begin{tabular}{|c|c|c|c|c|c|c|}
\hline \multirow{2}{*}{ Source } & \multicolumn{5}{|c|}{ Components } & \multirow{2}{*}{ Reference } \\
\hline & Glucan & Xylan & Lignin & Ash & Extractives & \\
\hline OPFB & 42.8 & 20.9 & 31.9 & 0.8 & 3.6 & This study \\
\hline Sugarcane bagasse & 42.0 & 21.6 & 24.7 & 3.5 & 3.5 & Carvalho et al. (2018) \\
\hline Rice straw & 31.1 & 18.7 & 13.3 & 14.5 & 9.0 & Chen et al. (2011) \\
\hline Corn stover & 31.5 & 15.4 & 14.1 & 7.9 & 25.9 & Vergara et al. (2018) \\
\hline Wheat straw & 32.8 & 26.3 & 13.8 & 17.0 & 4.1 & Vergara et al. (2018) \\
\hline
\end{tabular}

Note: OPFB - oil palm frond bagasse. 
TABLE 3. EXPERIMENTAL DESIGN LAYOUT USING $2^{5-1}$ FRACTIONAL FACTORIAL DESIGN FOR ACID PRETREATMENT WITH RESPONSES

\begin{tabular}{|c|c|c|c|c|c|c|c|c|}
\hline \multirow{2}{*}{$\begin{array}{c}\text { Standard } \\
\text { order }\end{array}$} & \multicolumn{5}{|c|}{ Variables } & \multicolumn{3}{|c|}{ Responses (\%) } \\
\hline & A & B & $\mathrm{C}$ & $\mathbf{D}$ & $\mathrm{E}$ & Glucan & Xylan & Lignin \\
\hline 1 & -1 & -1 & -1 & -1 & +1 & 51.39 & 23.64 & 17.58 \\
\hline 2 & +1 & -1 & -1 & -1 & -1 & 47.06 & 22.18 & 26.95 \\
\hline 3 & -1 & +1 & -1 & -1 & -1 & 57.02 & 27.63 & 15.03 \\
\hline 4 & +1 & +1 & -1 & -1 & +1 & 49.83 & 22.78 & 21.07 \\
\hline 5 & -1 & -1 & +1 & -1 & -1 & 53.06 & 23.80 & 22.53 \\
\hline 6 & +1 & -1 & +1 & -1 & +1 & 56.75 & 25.85 & 17.29 \\
\hline 7 & -1 & +1 & +1 & -1 & +1 & 52.73 & 23.25 & 23.76 \\
\hline 8 & +1 & +1 & +1 & -1 & -1 & 73.33 & 0.00 & 26.66 \\
\hline 9 & -1 & -1 & -1 & +1 & -1 & 54.50 & 25.43 & 18.95 \\
\hline 10 & +1 & -1 & -1 & +1 & +1 & 62.51 & 17.00 & 20.40 \\
\hline 11 & -1 & +1 & -1 & +1 & +1 & 50.56 & 22.46 & 21.53 \\
\hline 12 & +1 & +1 & -1 & +1 & -1 & 60.15 & 16.56 & 19.95 \\
\hline 13 & -1 & -1 & +1 & +1 & +1 & 49.32 & 21.08 & 19.11 \\
\hline 14 & +1 & -1 & +1 & +1 & -1 & 58.41 & 14.8 & 23.68 \\
\hline 15 & -1 & +1 & +1 & +1 & -1 & 49.01 & 21.03 & 26.41 \\
\hline 16 & +1 & +1 & +1 & +1 & +1 & 64.06 & 0.00 & 31.33 \\
\hline
\end{tabular}

Note: A - temperature $\left({ }^{\circ} \mathrm{C}\right) ; \mathrm{B}$ - reaction time (hr); C - solid loading $(\%)$; D - acid concentration (\%); E - agitation (rpm).

with $0.01 \%$ acid concentration at $90^{\circ} \mathrm{C}$ for $24 \mathrm{hr}$ without agitation, resulting in the amount of glucan and lignin of $73.33 \%$ and $26.66 \%$, respectively. Whereas, standard order run 16 which was incubated at $90^{\circ} \mathrm{C}$ for $24 \mathrm{hr}$ involving mixing with $20 \%$ solid loading and $1.0 \%$ acid concentration had obtained $64.06 \%$ glucan and $31.33 \%$ lignin content. From the data, it can be identified that the complete removal of xylan happened when the pretreatment was performed at high temperature $\left(90^{\circ} \mathrm{C}\right)$, while the maximum xylan recovery (Standard Order 3) was attained when low temperature $\left(37^{\circ} \mathrm{C}\right)$ was applied even with the same pretreatment duration and acid concentration. The results indicate that temperature has very significant adverse impacts on the retention of xylan without considering changes in acid concentration and agitation conditions. The variation of xylan content at high and low operating temperature can also be confirmed from previous studies. When Hsu et al. (2010) performed sulphuric acid pretreatment on rice straw by varying the temperature between $160^{\circ} \mathrm{C}-190^{\circ} \mathrm{C}$ and acid concentration of $0.5 \%-1.0 \%$, the preserved xylan in solid residue rice straw were between $0.7 \%-$ $5.1 \%$ after the pretreatment. On the other hand, Gowdhaman and Ponnusami (2015) has recovered about $14.7 \%$ xylan in corncorb after the pretreatment which was performed using $0.1 \% \mathrm{H}_{2} \mathrm{SO}_{4}$ at $60^{\circ} \mathrm{C}$. This gives an early view on the factor that contributed in pretreatment process.
It also can be observed that overall, when xylan content was at its minimum, higher amount of glucan and lignin were attained. According to Chen et al. (2011), xylan removal could increase glucan and lignin content resulted from the acid-catalysed hydrolysis of xylan. In this study, the maximum xylan content (Standard Order 3) and zero percent of xylan (Standard Order 8 and 16) were achieved when the pretreatment was performed for $24 \mathrm{hr}$, when operated at $37^{\circ} \mathrm{C}$ and $90^{\circ} \mathrm{C}$, respectively. Even with the same reaction time, opposite results were achieved. This happened because at certain condition when using acid as a pretreatment medium, xylan will be degraded into its monomeric sugar, xylose, which accumulated in the liquid fraction of hydrolysate. Besides, if the process period is prolonged, xylose in hydrolysate will further transform into inhibitors like furfural and acetic acid (Vergara et al., 2018). Thus, the implementation of acid pretreatment very much controlled by the combined severity concept of factors involved in the process depending on the targeted material (Jung and Kim, 2015).

\section{Statistical Analysis and Model Equation}

The data obtained in Table 3 were analysed for the construction of glucan, xylan and lignin equation models by the Design Expert software. The final model equations generated explain the 
relationship between the pretreatment condition with the amount of glucan, xylan and lignin are illustrated in Equation (4), Equation (5) and Equation (6), respectively.

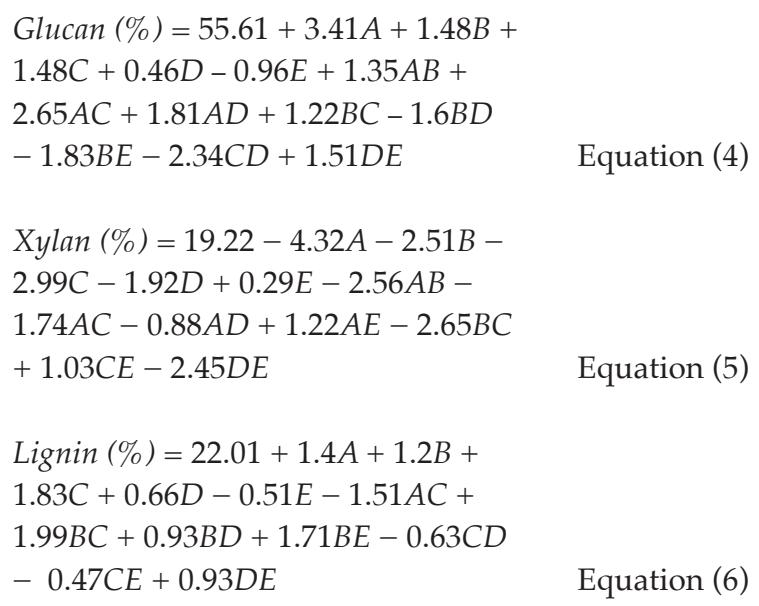

where temperature, reaction time, solid loading, acid concentration and agitation are the main effects of pretreatment condition denoted by A, B, C, D and $\mathrm{E}$, respectively. Meanwhile, the interaction effects are referred by $\mathrm{AB}, \mathrm{AC}, \mathrm{AD}, \mathrm{AE}, \mathrm{BC}, \mathrm{BD}, \mathrm{BE}, \mathrm{CD}$, CE and DE.

Statistical analysis of glucan, xylan and lignin responses were further analysed through analysis of variance (ANOVA) to assess the significance of each models (Table 4). The ANOVA results revealed that the models of glucan, xylan and lignin obtained are significant at F-value of 30.86, 230.47 and 19.05, respectively. In addition, the $p$-values for all models are less than 0.05 , which are considered statistically significant. Furthermore, the models are also significant, with $R^{2}$ values of $0.9950,0.9989$ and 0.9870 , respectively. The $R^{2}$ should not be less than 0.80 for a good model (Lin et al., 2017). The recorded values imply that only $0.5 \%, 0.11 \%$ and $1.3 \%$ of the models have the variability between experimental and predicted data.

\begin{tabular}{lccc}
\multicolumn{4}{c}{ TABLE 4. STATISTICAL ANALYSIS OF GLUCAN, } \\
XYLAN AND LIGNIN MODELS \\
Response & Glucan & Xylan & Lignin \\
\hline Model & Significant & Significant & Significant \\
-value & 30.86 & 230.47 & 19.05 \\
-value & 0.0318 & 0.0004 & 0.0166 \\
& 0.9950 & 0.9989 & 0.9870 \\
djusted $R^{2}$ & 0.9628 & 0.9946 & 0.9352 \\
\hline
\end{tabular}

Further detailed analysis of variance for xylan recovery via diluted nitric acid pretreatment is displayed in Table 5. All factors, except for agitation, are significant in affecting xylan content. Temperature is the most significant factor affecting the pretreatment at probability of $<0.0001$. Solid loading, reaction time and acid concentration follow the significant ranks with $p$-values of $0.0003,0.0005$ and 0.0011 , respectively. Agitation, by contrast, is shown to be statistically insignificant in improving xylan recovery, as its $p$-value exceeds $0.05(0.1521)$. The result indicates that any changes in agitation with or without the condition will not affect xylan recovery. In terms of interaction, all interactions are considered statistically significant in determining xylan content with $p$-value below 0.05 .

TABLE 5. ANALYSIS OF VARIANCE OF FACTORS AFFECTING ACID PRETREATMENT ON XYLAN RECOVERY

\begin{tabular}{lrrrrr}
\hline \multicolumn{1}{c}{ Source } & $\begin{array}{c}\text { Sum of } \\
\text { squares }\end{array}$ & Df & $\begin{array}{c}\text { Mean } \\
\text { square }\end{array}$ & F-value & $p$-value \\
\hline A-Temperature & 298.93 & 1 & 298.93 & 812.2 & $<0.0001$ \\
B-Reaction time & 100.41 & 1 & 100.41 & 272.82 & 0.0005 \\
C-Solid loading & 143.12 & 1 & 143.12 & 388.86 & 0.0003 \\
D-Acid concentration & 59.18 & 1 & 59.18 & 160.8 & 0.0011 \\
E-Agitation & 1.34 & 1 & 1.34 & 3.65 & 0.1521 \\
AB & 104.57 & 1 & 104.57 & 284.11 & 0.0005 \\
AC & 48.58 & 1 & 48.58 & 132 & 0.0014 \\
AD & 12.49 & 1 & 12.49 & 33.93 & 0.0101 \\
AE & 23.89 & 1 & 23.89 & 64.9 & 0.004 \\
BC & 112.43 & 1 & 112.43 & 305.47 & 0.0004 \\
CE & 16.97 & 1 & 16.97 & 46.11 & 0.0065 \\
DE & 95.97 & 1 & 95.97 & 260.77 & 0.0005 \\
Residual & 1.10 & 3 & 0.37 & - & - \\
Cor. total & 1018.98 & 15 & - & - & - \\
\hline
\end{tabular}


Analysis the Main and Interaction Effects for Xylan Recovery

Pareto chart as seen in Figure 1 describes the significant level of each main and interaction factor affecting acid pretreatment. The evaluation was only performed on xylan recovery, to study how the factors influencing its content. The varied range of $\mathrm{t}$-values of effect observed for each factor are proportional to the height of the bars where the numerical effects is divided by its associated standard error to compute the values (Anderson and Whitcomb, 2007). It visualises the significance of factors using two limit values of the Bonferroni limit and the $\mathrm{t}$-value limit as the reference point for defining the significant factors. The degree of significance of the effects decrease as the bars move from left to right with the reduction of the bars height (Wilkinson, 2006). In this case, factor A (temperature) is the most significant factor with the highest $\mathrm{t}$-value while factor $\mathrm{E}$ (agitation) is least significant factor for the pretreatment process.

The limits are measured based on $t$-value of effects. Factors with $\mathrm{t}$-value which exceeded the Bonferroni limit at 8.57517 is considered important and may considerably improve the xylan recovery (Abdulredha et al., 2020). The chart provides a $\mathrm{t}$-value of effects beyond the Bonferroni limit for the main factors $\mathrm{A}, \mathrm{B}, \mathrm{C}$ and $\mathrm{D}$ and interactions of $\mathrm{BC}, \mathrm{AB}, \mathrm{DE}$ and $\mathrm{AC}$. These factors are important to influence the acid pretreatment process. The factors with an effect $t$-value between the limits of Bonferroni and t-value could be important for the pretreatment process (Alara et al., 2017). The interactions of $\mathrm{AE}, \mathrm{CE}$ and $\mathrm{AD}$ are significant for the process and might improve the diluted nitric acid pretreatment process. When evaluating xylan content however, factors with $\mathrm{t}$-value of effect underneath the t-value limit at 3.18245 are not considered significant.

The Pareto chart is also useful to demonstrate the positive and negative effects possess by each factor. Positive and negative effects are presented by orange and blue bars, respectively. Positive effects show that the xylan content increases as the factor level increases, while negative effects illustrate the opposite (Mah et al., 2016). In this study, the main factor $E$ has a positive effect in which the increasing factor value had increased the content of xylan. As for interaction, $\mathrm{AE}$ and $\mathrm{CE}$ have positive effects where agitation at higher temperatures and solid loading is necessary to increase the recovery of xylan compared to without agitation. However, the main factors of A, B, C and D have shown negative effects, whereby a decline of each value had increased the xylan content. Similarly, the interaction of $A B$, $\mathrm{AC}, \mathrm{BC}$ and $\mathrm{DE}$ also resulted in negative effects, resulting in an increase of xylan content, as the interaction between temperature and reaction time, temperature and solid loading, reaction time and solid loading, and acid concentration and agitation decreased. These results indicated an advantage of high xylan recovery obtained at mild pretreatment conditions, therefore minimising the production cost.

The percentage of contribution is another method to represent the influence of factors toward acid pretreatment process. Table 6 shows the contribution of each factor in affecting xylan recovery. Temperature showed the highest contribution at $29.34 \%$. The percentage contribution corresponds to the $\mathrm{t}$-value of effects (Figure 1). The

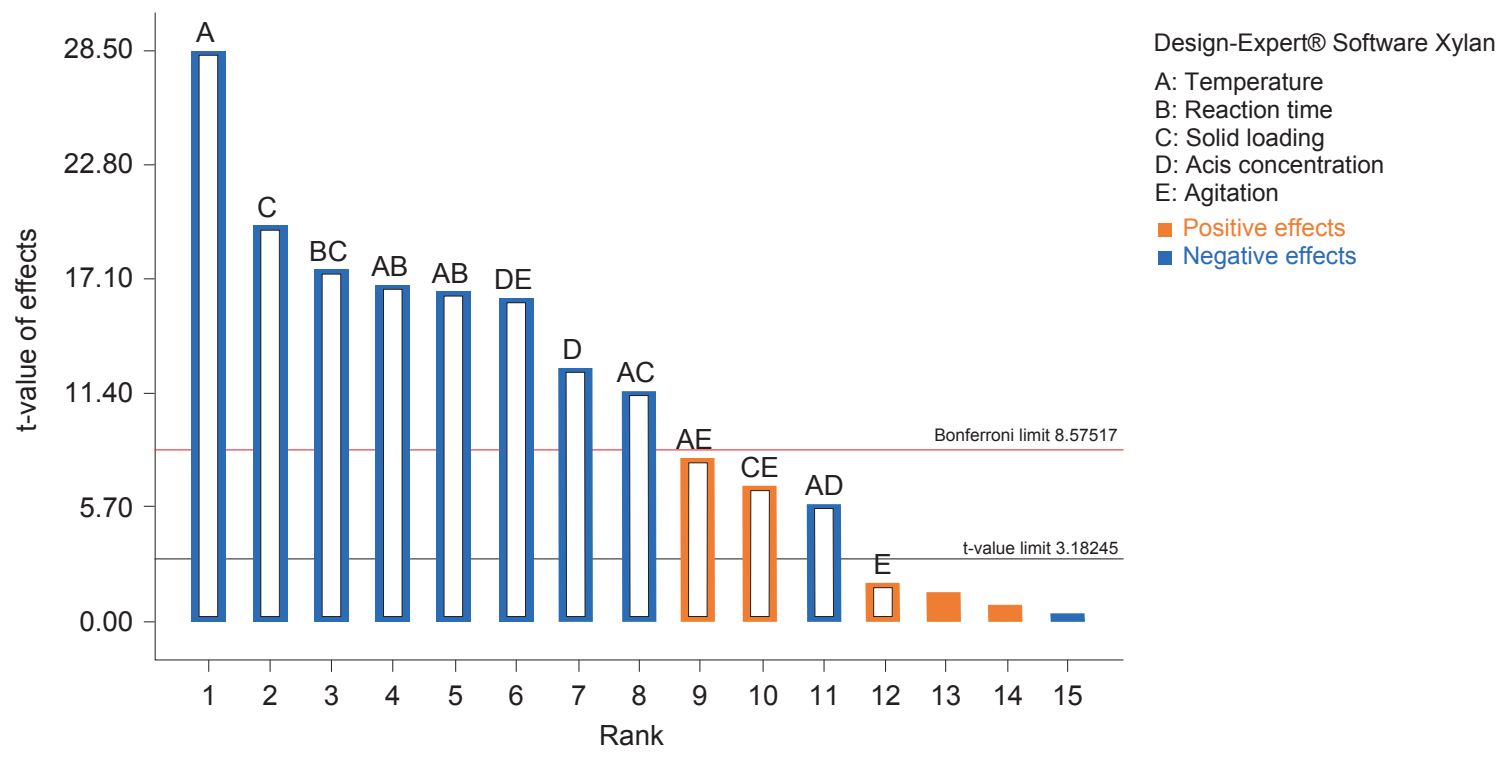

Figure 1. Pareto chart for factors affecting xylan content. 
factors with a percentage contribution of less than $1 \%$ were excluded from the research in this report. The reduction of insignificant factors may improve the model constructed by the Design Expert software. However, the main effect of agitation (0.13) was kept in the analysis to support hierarchy.

TABLE 6. PERCENTAGE CONTRIBUTION OF FACTORS AFFECTING XYLAN CONTENT

\begin{tabular}{lc}
\hline Term & \% contribution \\
\hline A-Temperature & 29.34 \\
B-Reaction time & 9.85 \\
C-Solid loading & 14.05 \\
D-Acid concentration & 5.81 \\
E-Agitation & 0.13 \\
AB & 10.26 \\
AC & 4.77 \\
AD & 1.23 \\
AE & 2.34 \\
BC & 11.03 \\
BD & 0.08 \\
BE & 0.02 \\
CD & 0.01 \\
CE & 1.67 \\
DE & 9.42 \\
\hline
\end{tabular}

\section{Effects of Different Variables on Xylan Recovery}

Figure 2 displays the temperature plot as the most significant factor that affects the acid pretreatment process for xylan recovery. A high xylan content was observed at low temperature. High temperature could result in the degradation of hemicellulose (xylan) and conversion of xylan into sugar (xylose). In fact, excessive temperature may cause the formation of furfural from the xylose and increases the degradation of cellulose (glucan) (Ji et al., 2017).

Figure 3 illustrates the interaction effects of several significant interaction factors involved in affecting xylan recovery. Figure $3 a$ demonstrates the interaction between temperature and reaction time (AB). A high xylan content was observed at $37^{\circ} \mathrm{C}$ although the reaction time was increased. However, the xylan content was greatly reduced as reaction time was increased at $90^{\circ} \mathrm{C}$. The results indicate that at high temperature $\left(90^{\circ} \mathrm{C}\right)$ and longer reaction time ( $24 \mathrm{hr})$, most of xylan content might be converted into xylose. Likewise, a similar trend was observed in the interaction between temperature and solid loading (AC), where the xylan content was greatly increased at $37^{\circ} \mathrm{C}$. In this case, the change of solid loading was less significant than the change of temperature from high to low. The result shows that the xylan recovery increased at lower temperature for both high- and low-level solid loadings. However, it was observed that the xylan recovery was consistently higher at $5 \%$ solid loading compared to that at $20 \%$ solid loading. Less interaction between the factors can be shown by the two lines (almost parallel) which represent the degree of significance. Paralleled lines designate that there is no interaction between the factors and vice versa (Kim, 2016).

The interaction between reaction time and solid loading (BC) presented the highest impact in xylan content as reflected in Figure 3c. A substantial difference of xylan recovery was observed when different level of solid loading was provided at longer reaction time. At low level solid loading, higher lignin content could be removed since most lignocellulosic biomass surface may expose to be hydrolysed by dilute nitric acid, resulting in high xylan recovery. In fact, acid hydrolysation of lignin could be completed at a shorter reaction time as the xylan content was almost constant, even though the reaction time was extended by $6-24 \mathrm{hr}$. Meanwhile, the interaction between acid concentration and agitation (DE) is different from the interactions of $A B, A C$ and $B C$. The two lines intersect which highlights the significant interaction between the factors. High xylan content was recovered at low acid concentration with agitation compared to that without agitation. Agitation could improve the pretreatment efficiency by increasing the acid hydrolysis accessibility to lignocellulosic biomass (Loow et al., 2016). Several studies applied mild agitation to mix liquid and solid to improve pretreatment process (Rajagopalan et al., 2017; Romero-Fernández et al., 2018). However, the xylan

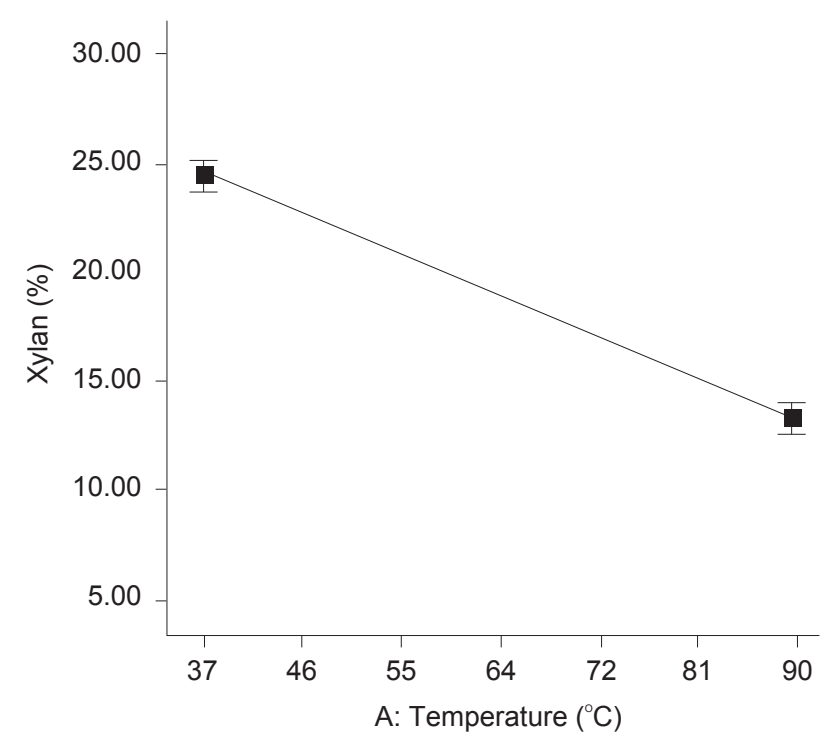

Figure 2. Plot of the temperature in affecting xylan recovery. 

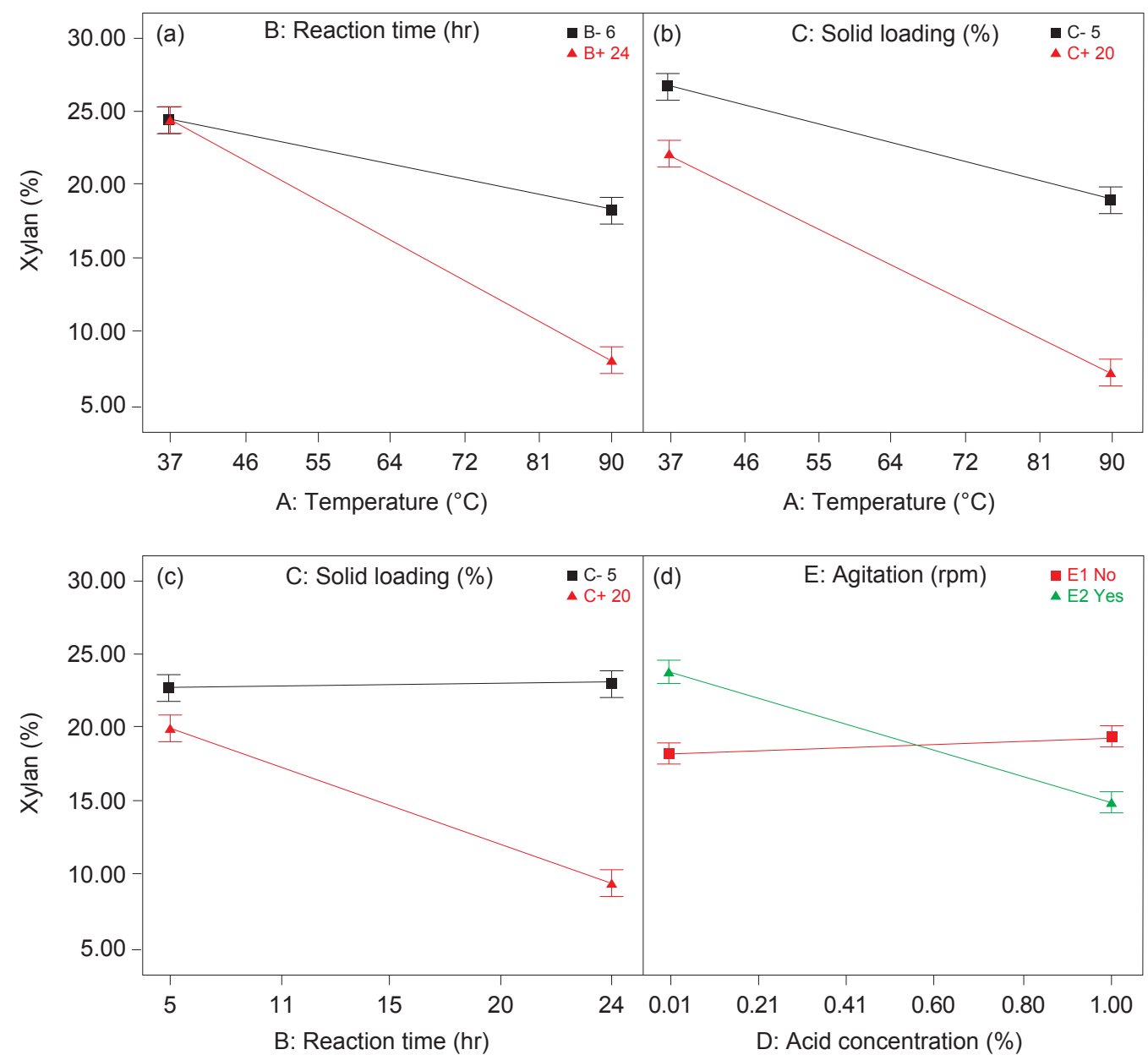

Figure 3. Plot of the significant interaction effects between (a) temperature and reaction time, (b) temperature and solid loading, (c) reaction time and solid loading, and (d) acid concentration and agitation.

content had reduced when the acid concentration was increased to $1 \%$, which could be attributable to xylan hydrolysation at higher concentration and the deterioration was also further accelerated by the aid of agitation. This result can be further understood by comparing xylan recovery at similar acid concentration (1\%) with and without agitation, where higher xylan recovery was obtained when the pretreatment was performed without agitation. This result is supported by the findings of other studies where no agitation was provided to enhance pretreatment (Palamae et al., 2017; Sporck et al., 2017; Vergara et al., 2018).

\section{Model Validation}

Model validation was performed by predetermining the preference of product recovery through the Design Expert setting. This study aims to increase xylan content and reduce the content of lignin simultaneously. Hence, higher yield of xylan and low lignin observed after pretreatment is considered successful and thus, could proceed to facilitate enzymatic hydrolysis in further study to obtain the higher valuable product recovery such as production of xylooligosaccharides. As expected, glucan content was unaffected by the diluted nitric acid pretreatment process since disruption of glucan may only occur with the removal of xylan at high level condition (Xu et al., 2013). In this case, preservation of glucan may indirectly improve xylan recovery by preventing acid hydrolysis of xylan. Triplicate validation tests were carried out to confirm the adequacy of the xylan recovery model obtained based on the conditions recommended by Design Expert software (Figure 4). By setting glucan to be in range, xylan to be maximum and lignin to be minimum, the best condition was proposed: $37^{\circ} \mathrm{C}$, reaction time of $24 \mathrm{hr}$, solid loading of $5 \%$, and acid concentration at $0.01 \%$ without agitation, with the predicted values for glucan, xylan, and lignin of $57.19 \%, 28.04 \%$ and $15.78 \%$, respectively.

The experimental results of glucan, xylan, and lignin contents were $54.53 \pm 0.07 \%, 25.89 \pm 0.73 \%$ and $16.48 \pm 0.18 \%$, with the percentage errors of $4.43 \%, 7.69 \%$ and $4.43 \%$ respectively. The low percentage errors (less than 10\%) observed in this study indicated that the experimental and predicted 


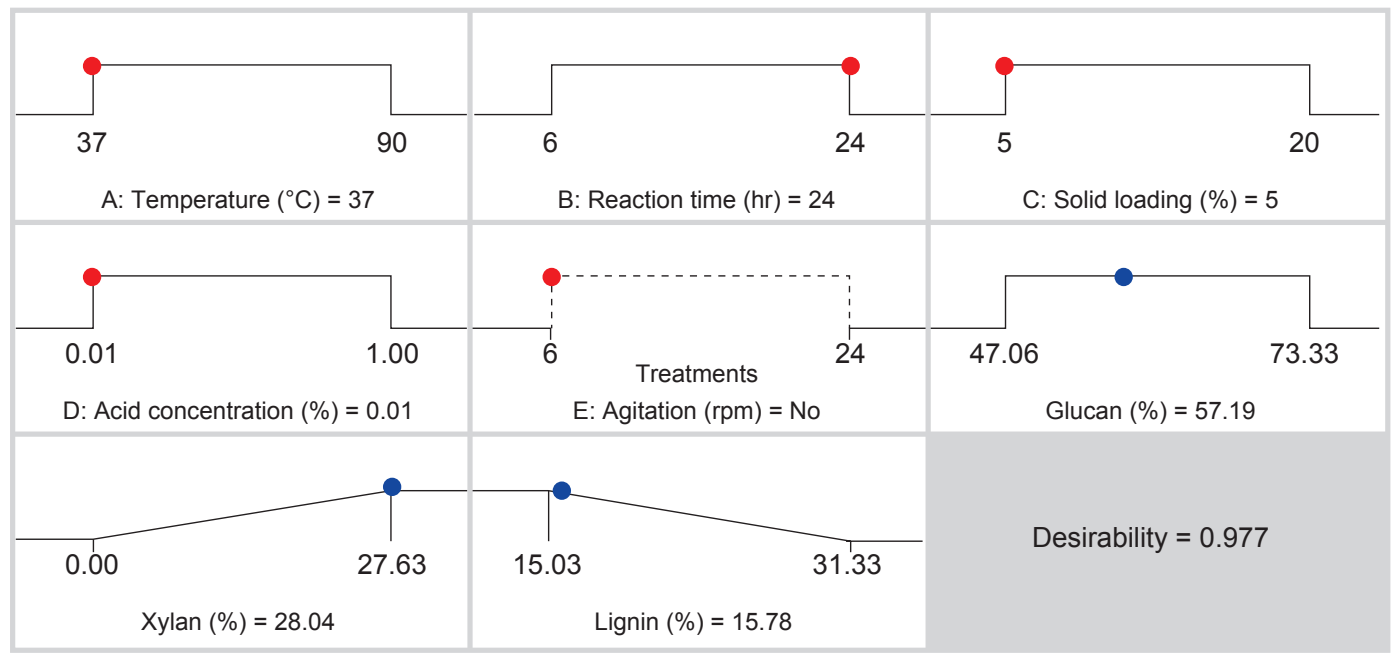

Figure 4. Best condition suggested by Design Expert software for maximum xylan recovery.

data are in close agreement thus, confirmed the suitability and adequacy of the model equations to predict the responses. Hence, a promising high xylan recovery at high lignin removal could be reproduced in the future using the verified model.

\section{CONCLUSION}

Studying on factors affecting acid pretreatment on xylan recovery have found the best condition points to prevent excessive acid hydrolysation of xylan from OPFB. These results found that temperature is most critical for the pretreatment process to be controlled. Diluted nitric acid pretreatment under mild conditions for $24 \mathrm{hr}$ has resulted in a successful recovery of up to $27.63 \%$ of the xylan content. On the contrary, rising conditions resulted in the complete removal of xylan from the plant material due to xylan hydrolysis. Model equations for glucan, xylan and lignin produced are significant to illustrate the relationship between the factors and the response with validation percentage error between $4.43 \%$ and $7.69 \%$. The study suggests that pretreatment with diluted nitric acid is one of the most advantageous one-step pretreatment processes to improve xylan recovery under mild pretreatment conditions.

\section{ACKNOWLEDGEMENT}

This work was supported by the Ministry of Education Malaysia (LRGS/2013/UKM-UKM/ PT/01 and RDU1803115); and the Universiti Malaysia Pahang (GRS1803112). The authors wish to express their gratitude to the Faculty of Chemical and Process Engineering Technology, Universiti Malaysia Pahang (UMP) for making this work possible.

\section{REFERENCES}

Abdulredha, M M; Hussain, S A and Abdullah, L C (2020). Optimization of the demulsification of water in oil emulsion via non-ionic surfactant by the response surface methods. J. Pet. Sci. Eng., 184: 106463.

Abu Sepian, N R; Mat Yasin, N H and Zainol, N (2019). Evaluation of factors for cells growth of immobilized Chlorella vulgaris via factorial design approach. Chem. Eng. Commun., 208(5): 601-612.

Agbor, V B; Cicek, N; Sparling, R; Berlin, A and Levin, D B (2011). Biomass pretreatment: Fundamentals toward application. Biotechnol. Adv., 29(6): 675-685.

Alara, O R; Abdurahman, N H and Olalere, O A (2017). Ethanolic extraction of flavonoids, phenolics and antioxidants from Vernonia amygdalina leaf using two-level factorial design. J. King Saud Univ. - Sci., 32(1): 7-16.

Anderson, $\mathrm{M}$ and Whitcomb, P (2007). Chapter 3: Two-level factorial design. DOE Simplified: Practical Tools for Effective Experimentation (Mark J Anderson, P J W ed.). p. 1-30. CRC Press, Boca Raton.

Asim, A M; Uroos, M; Naz, S; Sultan, M; Griffin, G; Muhammad, N and Khan, A S (2019). Acidic ionic liquids: Promising and cost-effective solvents for processing of lignocellulosic biomass. J. Mol. Liq., 287: 110943.

Awalludin, M F; Sulaiman, O; Hashim, R and Nadhari, W N A W (2015). An overview of the oil palm industry in Malaysia and its waste utilization through thermochemical conversion, specifically 
via liquefaction. Renew. Sustain. Energy Rev., 50: 1469-1484.

Box, G E P and Wilson, K B (1951). On the experimental attainment of optimum conditions. J. R. Stat. Soc., 13(1): 1-45.

Carvalho, A F A; Neto, P de O; da Silva, D F and Pastore, G M (2013). Xylo-oligosaccharides from lignocellulosic materials: Chemical structure, health benefits and production by chemical and enzymatic hydrolysis. Food Res. Int., 51(1): 75-85.

Chen, W-H; Pen, B-L; Yu, C-T and Hwang, W-S (2011). Pretreatment efficiency and structural characterization of rice straw by an integrated process of dilute-acid and steam explosion for bioethanol production. Bioresour. Technol., 102(3): 2916-2924.

Dai, L; Wang, Y; Liu, Y; Ruan, R; He, C; Yu, Z; Jiang, L; Zeng, Z and Tian, X (2019). Integrated process of lignocellulosic biomass torrefaction and pyrolysis for upgrading bio-oil production: A state-of-the-art review. Renew. Sustain. Energy Rev., 107: 20-36.

Faizi, M; Shahriman, A; Majid, M A; Shamsul, B; Ng, Y; Basah, S; Cheng, E; Afendi, M; Zuradzman, $\mathrm{M}$ and Wan, K (2017). An overview of the oil palm empty fruit bunch (OPEFB) potential as reinforcing fibre in polymer composite for energy absorption applications. MATEC Web of Conferences. p. 01064.

Goh, C S; Lee, K T and Bhatia, S (2010). Hot compressed water pretreatment of oil palm fronds to enhance glucose recovery for production of second generation bio-ethanol. Bioresour. Technol., 101(19): 7362-7367.

Gowdhaman, D and Ponnusami, V (2015). Production and optimization of xylooligosaccharides from corncob by Bacillus aerophilus KGJ2 xylanase and its antioxidant potential. Int. J. Biol. Macromol., 79: 595-600.

He, Y; Fang, Z; Zhang, J; Li, X and Bao, J (2014). De-ashing treatment of corn stover improves the efficiencies of enzymatic hydrolysis and consequent ethanol fermentation. Bioresour. Technol., 169: 552-558.

Hernández, E; García, A; López, M; Puls, J; Parajó, J C and Martín, C (2013). Dilute sulphuric acid pretreatment and enzymatic hydrolysis of Moringa oleifera empty pods. Ind. Crops Prod., 44: 227-231.

Hsu, T C; Guo, G L; Chen, W H and Hwang, W $S$ (2010). Effect of dilute acid pretreatment of rice straw on structural properties and enzymatic hydrolysis. Bioresour. Technol., 101(13): 4907-4913.

Ji, X; Ma, H; Tian, Z; Lyu, G; Fang, G; Chen, J and Saeed, H A M (2017). Production of xylose from diluted sulfuric acid hydrolysis of wheat straw. BioRes., 12(4): 7084-7095.

Jönsson, L J and Martín, C (2016). Pretreatment of lignocellulose: Formation of inhibitory byproducts and strategies for minimizing their effects. Bioresour. Technol., 199: 103-112.

Jung, Y H and Kim, KH (2015). Acidic pretreatment. Pretreatment of Biomass: Processes and Technologies (Pandey, A; Negi, S; Binod, P and Larroche, C eds.). Elsevier. p. 27-50.

Kim, S-C (2016). Application of response surface method as an experimental design to optimize coagulation-flocculation process for pretreating paper wastewater. J. Ind. Eng. Chem., 38: 93-102.

Kumar, P; Barrett, D M; Delwiche, M J and Stroeve, P (2009). Methods for pretreatment of lignocellulosic biomass for efficient hydrolysis and biofuel production. Ind. Eng. Chem. Res., 48(8): 3713-3729.

Kumari, D and Singh, R (2018). Pretreatment of lignocellulosic wastes for biofuel production: A critical review. Renew. Sustain. Energy Rev., 90 (May 2017): 877-891.

Lee, J W; Kim, J Y; Jang, H M; Lee, M W and Park, J M (2015). Sequential dilute acid and alkali pretreatment of corn stover: Sugar recovery efficiency and structural characterization. Bioresour. Technol., 182: 296-301.

Lin, Q; Li, H; Ren, J; Deng, A; Li, W; Liu, C and Sun, R (2017). Production of xylooligosaccharides by microwave-induced, organic acid-catalyzed hydrolysis of different xylan-type hemicelluloses: Optimization by response surface methodology. Carbohydr. Polym., 157: 214-225.

Loow, Y L; Wu, T Y; Jahim, J M; Mohammad, A W and Teoh, W H (2016). Typical conversion of lignocellulosic biomass into reducing sugars using dilute acid hydrolysis and alkaline pretreatment. Cellulose, 23(3): 1491-1520.

Lyu, H; Zhou, J; Lyu, C; Meng, F; Geng, Z and Zhang, M (2018). Exploration and optimization of mixed acid synergistic catalysis pretreatment for maximum C5 sugars. Bioresour. Technol., 260: 53-60. 
Mah, K H; Yussof, H W; Seman, M N A and Mohammad, A W (2016). Separation of xylose using a thin-film composite nanofiltration membrane: Screening of interfacial polymerization factors. RSC Adv., 6(73): 69454-69464.

Martín, C; Peinemann, J C; Wei, M; Stagge, S; Xiong, S and Jönsson, L J (2019). Dilute-sulfuric acid pretreatment of de-starched cassava stems for enhancing the enzymatic convertibility and total glucan recovery. Ind. Crops Prod., 132: 301-310.

Martínez-Patiño, J C; Lu-Chau, T A; Gullón, B; Ruiz, E; Romero, I; Castro, E and Lema, J M (2018). Application of a combined fungal and diluted acid pretreatment on olive tree biomass. Ind. Crops Prod., 121: 10-17.

Mesa, L; Martínez, Y; Barrio, E and González, E (2017). Desirability function for optimization of dilute acid pretreatment of sugarcane straw for ethanol production and preliminary economic analysis based in three fermentation configurations. Appl. Energy, 198: 299-311.

Noorshamsiana, A W; Nur Eliyanti, A O; Fatiha, I and Astimar, A A (2017). A review on extraction processes of lignocellulosic chemicals from oil palm biomass. J. Oil Palm Res., 29(4): 512-527.

Palamae, S; Dechatiwongse, P; Choorit, W; Chisti, Y and Prasertsan, P (2017). Cellulose and hemicellulose recovery from oil palm empty fruit bunch (EFB) fibers and production of sugars from the fibers. Carbohydr. Polym., 155: 491-497.

Rajagopalan, G; Shanmugavelu, K and Yang, K-L (2017). Production of prebioticxylooligosaccharides from alkali pretreated mahogany and mango wood sawdust by using purified xylanase of Clostridium strain BOH3. Carbohydr. Polym., 167: 158-166.

Romaní, A; Tomaz, P D; Garrote, G; Teixeira, J A and Domingues, L (2016). Combined alkali and hydrothermal pretreatments for oat straw valorization within a biorefinery concept. Bioresour. Technol., 220: 323-332.

Romero-Fernández, M; Moreno-Perez, S; Martins de Oliveira, S; Santamaría, R I; Guisan, J M and Rocha-Martin, J (2018). Preparation of a robust immobilized biocatalyst of $\beta$-1,4-endoxylanase by surface coating with polymers for production of xylooligosaccharides from different xylan sources. N. Biotechnol., 44: 50-58.

Singh, R D; Banerjee, J; Sasmal, S; Muir, J and Arora, A (2018). High xylan recovery using two stage alkali pre-treatment process from high lignin biomass and its valorisation to xylooligosaccharides of low degree of polymerisation. Bioresour. Technol., 256: 110-117.

Sluiter, A; Hames, B; Ruiz, R; Scarlata, C; Sluiter, J; Templeton, D and Crocker, D (2012). Determination of structural carbohydrates and lignin in biomass: Laboratory Analytical Procedure (LAP). Vol. 1617. National Renewable Energy Laboratory.

Sluiter, A; Ruiz, R; Scarlata, C; Sluiter, J and Templeton, D (2008). Determination of extractives in biomass: Laboratory Analytical Procedure (LAP).

Soares, I B; Mendes, K C S; Benachour, M and Abreu, C A M (2017). Evaluation of the effects of operational parameters in the pretreatment of sugarcane bagasse with diluted sulfuric acid using analysis of variance. Chem. Eng. Commun., 204(12): 1369-1390.

Solarte-Toro, J C; Chacón-Pérez, Y and CardonaAlzate, C A (2018). Evaluation of biogas and syngas as energy vectors for heat and power generation using lignocellulosic biomass as raw material. Electron. J. Biotechnol., 33: 52-62.

Soplah, S; Abdullah, S; Shirai, Y; Kamal, E and Ali, M (2015). Fresh oil palm frond juice as a renewable, non-food, non-cellulosic and complete medium for direct bioethanol production. Ind. Crop. Prod., 63: 357-361.

Sporck, D; Reinoso, F A M; Rencoret, J; Gutiérrez, A; Del Rio, J C; Ferraz, A and Milagres, A M F (2017). Xylan extraction from pretreated sugarcane bagasse using alkaline and enzymatic approaches. Biotechnol. Biofuels, 10: 296-306.

Swain, M R and Krishnan, C (2015). Improved conversion of rice straw to ethanol and xylitol by combination of moderate temperature ammonia pretreatment and sequential fermentation using Candida Tropicalis. Ind. Crops Prod., 77: 1039-1046.

Syazana Mohtar, S; Nur, T; Tengku, Z; Busu, M; Mujahid, A; Noor, M; Shaari, N and Mat, H (2017). An ionic liquid treatment and fractionation of cellulose, hemicellulose and lignin from oil palm empty fruit bunch. Carbohydr. Polym., 166: 291299.

Tan, J P; Jahim, J M; Harun, S; Wu, T Y and Mumtaz, T (2016). Utilization of oil palm fronds as a sustainable carbon source in biorefineries. Int. J. Hydrogen Energy, 41(8): 4896-4906. 
Vergara, P; Ladero, M; García-Ochoa, F and Villar, J C (2018). Pre-treatment of corn stover, Cynara cardunculus L. stems and wheat straw by ethanolwater and diluted sulfuric acid: Comparison under different energy input conditions. Bioresour. Technol., 270: 449-456.

Wan Omar, W N N and Amin, N A S (2016). Multi response optimization of oil palm frond pretreatment by ozonolysis. Ind. Crops Prod., 85: 389-402.

Wilkinson, L (2006). Revising the Pareto Chart. Am. Stat., 60(4): 332-334.

Wojtusik, M; Villar, J C; Zurita, M; Ladero, M and Garcia-Ochoa, F (2017). Study of the enzymatic activity inhibition on the saccharification of acid pretreated corn stover. Biomass Bioenergy, 98: 1-7.
Xiao, W and Clarkson, W W (1997). Acid solubilization of lignin and bioconversion of treated newsprint to methane. Biodegradation, 8(1): 61-66.

Xu, F; Shi, Y-C and Wang, D (2013). Towards understanding structural changes of photoperiodsensitive sorghum biomass during sulfuric acid pretreatment. Bioresour. Technol., 135: 704-709.

Zhang, L; Xi, G; Yu, K; Yu, H and Wang, X (2017). Furfural production from biomass-derived carbohydrates and lignocellulosic residues via heterogeneous acid catalysts. Ind. Crops Prod., 98: 68-75.

Zhang, R; Lu, X; Sun, Y; Wang, X and Zhang, S (2011). Modeling and optimization of dilute nitric acid hydrolysis on corn stover. J. Chem. Technol. Biotechnol., 86(2): 306-314. 